\title{
Clusters: Viscosity Cause?
}

\author{
V. P. Malyshev, A. M. Makasheva \\ Chemical and Metallurgical Institute after Name Zh. Abishev, Karaganda, Republic of Kazakhstan \\ Email: eia_hmi@mail.ru
}

How to cite this paper: Malyshev, V.P. and Makasheva, A.M. (2019) Clusters: Viscosity Cause? Open Journal of Physical Chemistry, 9, 107-125. https://doi.org/10.4236/ojpc.2019.93007

Received: May 14, 2019

Accepted: July 19, 2019

Published: July 22, 2019

Copyright $\odot 2019$ by author(s) and Scientific Research Publishing Inc. This work is licensed under the Creative Commons Attribution International License (CC BY 4.0).

http://creativecommons.org/licenses/by/4.0/

\begin{abstract}
The significance of the work is determined by the need to develop a cluster theory of the liquid state of a substance in order to more deeply substantiate the viscosity, which is still expressed by empirical parameters within the framework of ideal ideas about the stratified flow of a liquid. According to the reference data on the dynamic viscosity of the melts for chlorides of the first group of the Periodic System, the approximating dependences in the form of cluster-associate and Frenkel's models were constructed at various temperatures. The first model is based on taking into account the share of particles that cannot overcome the thermal melting barrier and thus serve to form virtual clusters and associates while preserving the structural motifs of the solid phase. In the framework of the cluster-associate viscosity model developed by the authors, these formations determine the melt viscosity and serve as flow units to which the energy of fluid motion is applied. The Frenkel's model allows us to estimate the activation energy of fluidity. Calculations show that by comparing this energy with the degree of cluster association obtained in the framework of the cluster-associate model, a fairly close linear correlation is obtained, and the proportionality coefficient has the meaning of the activation energy per cluster. This energy does not go beyond the van der Waals energy of the unsaturated intermolecular bond characteristic of the interaction of particles in a liquid. This confirms the earlier established by the authors a similar pattern for melts of simple substances, based on the understanding of fluidity as a consequence of the destruction of cluster associates while preserving the clusters themselves.
\end{abstract}

\section{Keywords}

Dynamic Viscosity, Cluster, Associate, Temperature, Fluidity, Activation Energy

\section{Introduction}

The prerequisites for this research are the wide use by the authors of the 
Boltzmann's distribution for expressing various properties of a substance based on taking into account the degree of its randomization, in particular, on plasticity, evaporation and grindability. The modern cluster theory of a fluid is based on the discovery of numerous virtual formations that retain the structural motifs of the solid phase using physical methods [1]-[18]. At the same time, only approximate qualitative relationships were found relating to the effect of temperature on the number and form of these formations. The authors of [19] [20] [21] for the first time substantiated the decisive influence of these formations on the viscosity of a liquid based on the concept of randomized particles put forward by them, subject to the Boltzmann's distribution and retaining their belonging to the virtual solid phase in a liquid according to the condition that they did not overcome the thermal melting barrier $R T_{m}$ in the entire liquid state range.

The proportion of these particles, called crystal-mobile, depends on the temperature according to the law

$$
R_{c r m}=1-\exp \left(-\frac{R T_{m}}{R T}\right)=1-\exp \left(-\frac{T_{m}}{T}\right) .
$$

The distribution of clusters according to the number of particles within them obeys a probabilistic pattern

$$
R_{c r m, n}=\left(1-R_{c r m}\right) P_{c r m}^{n},
$$

according to which the share of $n$-particle clusters decreases with increasing $n$ and decreasing $P_{c r m}$, that is, with increasing temperature. According to the authors [19], the viscosity is determined by the content of two- and more partial clusters, and the fluidity is determined by all single-particle clusters in the $P_{c r m}$ composition and by all single over-barrier particles. Thus, the proportion of particles responsible for the viscosity of the liquid, receives a quantitative expression

$$
R_{\eta}=1-\left[R_{c r m, 1}+\left(1-R_{c r m}\right)\right]=P_{c r m}^{2}=\left[1-\exp \left(-T_{m} / T\right)\right]^{2} .
$$

At the same time, the correlation of viscosity with the square of the share of crystal-mobile particles, close to linear, was revealed in [19] using the example of metals of the first group. This opened up the possibility of a transition to a natural expression of the temperature dependence of viscosity using arbitrary reference points $T_{i}, \eta_{i}$.

The most adequate form of adaptation of the fractional dependence of viscosity (3) to the natural one turned out to be the one that was observed primarily on the limits of viscosity change in the full temperature range with a transition to the dimensionless expression of viscosity at the reference point $\eta / \eta_{1}$

$$
\eta=\eta_{1}\left(T_{1} / T\right)^{a} .
$$

In this case, a clear dependence of the exponent a on temperature was found, which indicated its secondary influence on the viscosity. The authors of [19] [20] [21], based on the decreasing nature of the temperature variation of both the viscosity dependence and the exponent $a$, suggested that the secondary dependence is determined by the content of cluster associates, and the primary de- 
pendence is determined by the content of clusters. This led to the expression of the secondary dependence in the same form through the second reference point

$$
a=a_{2}\left(T_{2} / T\right)^{b} .
$$

In general, we obtained a hierarchical cluster-associate viscosity model

$$
\eta=\eta_{1}\left(T_{1} / T\right)^{a=a_{2}\left(T_{2} / T\right)^{b}},
$$

according to which it became possible not only to describe the experimental data most adequately, but also confidently extrapolate the dependence to the full range of the liquid state, and also to analyze the cluster-associate nature of a fluid in interrelation with its well-known models based on the internal unity of the structural and probabilistic approaches with the interpretation of viscosity not only as a structure-sensitive, but also chaos-sensitive property.

In this case, the parameters of the model (6) are determined by three reference points:

$$
\begin{gathered}
a_{2}=\frac{\ln \left(\eta_{2} / \eta_{1}\right)}{\ln \left(T_{1} / T_{2}\right)}, \\
b=\frac{\ln \frac{\ln \left(\eta_{3} / \eta_{1}\right) \ln \left(T_{1} / T_{2}\right)}{\ln \left(T_{1} / T_{3}\right) \ln \left(\eta_{2} / \eta_{1}\right)}}{\ln \left(T_{2} / T_{3}\right)} .
\end{gathered}
$$

The value of $b$ corresponds to the degree of aggregation of associates, that is, a more detailed hierarchical model of viscosity. As shown by calculations, this indicator differs little from one and can be taken constant for each substance. Apparently, the aggregation of associates is not as clearly expressed as the formation of clusters and their associates, and cannot be reliably identified given the low accuracy of the experimental definitions of viscosity, especially at elevated temperatures and a small number of reference points. It is possible that these inaccuracies for the most parts are accumulated and taken into account in the indicator $b$, which ensures, in general, a very high adaptation of the cluster-associate model to the experimental data [19].

\section{Methodical Part}

Usually, such an adaptation is achieved by linearizing a complex model with subsequent data processing on the parameters of the direct equation. In this case, such linearization is not mathematically possible with either a single or double logarithmization of the model (6).

The same applies, for example, to the Arrhenius equation for the reaction rate constant, if, in addition to the exponent, the effect of temperature is also taken into account in the pre-exponential factor, the so-called frequency factor, on the intensity of molecular collisions. Here, linearization is possible on the basis of a much smaller dependence of the frequency of collisions on temperature than in the exponential, which makes it possible to determine the activation energy in arrhenius coordinates $\ln k-1 / T$. 
To a greater extent, this circumstance is inherent in the Frenkel-Andrade's equation

$$
\eta=\frac{6 k T \tau_{0}}{\delta^{3}} \mathrm{e}^{\frac{\Delta W}{k T}}
$$

where $\delta$-the distance of one molecule jump to the adjacent monolayer of liquid, $\tau_{0}$-molecular oscillation period around equilibrium, $\Delta W$-jump activation energy. Here, the pre-exponential fraction can in fact also be referred to the collision frequency factor and therefore is usually taken as a constant value, at least for small temperature ranges, as is assumed in the Frenkel's equation

$$
\eta=\eta_{0} \mathrm{e}^{\frac{E}{R T}} .
$$

However, the formal analogy of the Frenkel's equation with the Arrhenius equation

$$
k=A \mathrm{e}^{-\frac{E}{R T}}
$$

this ends due to the opposite expression of the exponent of the fraction sign. As shown in [22], only the identity transformation of the Frenkel's equation by taking inverse values in the left and right sides of the equation

$$
\frac{1}{\eta}=\frac{1}{\eta_{0}} \mathrm{e}^{-\frac{E}{R T}}
$$

returns the exponent the original meaning of the probability of overcoming the thermal barrier based on the fundamental Boltzmann's distribution. In this case, inverse dimensional values, by definition, relate to fluidity, and the value of $E$ - to the activation energy of fluidity, and not viscosity, as it formally follows from the Frenkel's equation. The itself value of $E$ when processing the linearized Equation (10) remains unchanged.

Thus, the main characteristics of the viscosity of a fluid related to its nature in the Frenkel's model is the activation energy of fluidity, which can be determined by processing experimental data in a certain temperature range that allows adequate linearization in coordinates $\ln \eta-1 / T$.

In the cluster-associate model (6) it is possible to linearize in the same coordinates, assuming $a=$ const and reducing formula (6) to (4). However, the model is unnecessarily simplified, since it is determined through just one reference point and reduces to the type of power functions $\left(y=x^{a}\right)$, while the exponential dependencies are indicative of the type $\left(y=a^{x}\right)$. Only in its full form does the cluster-associate model acquire the greatest generality and adaptability, becoming an exponential-power function $\left(y=x^{x}\right)$. In this case, the average value of the degree of association of clusters $\bar{a}$ can be analytically determined on the basis of formula (5) as the average integral value

$$
\bar{a}=\frac{a_{2} T_{2}^{b}\left(T_{u p}^{1-b}-T_{l}^{1-b}\right)}{(1-b)\left(T_{u p}-T_{l}\right)},
$$

where $T_{\Gamma}$-low, $T_{u p}$-upper temperature range values. 
This interval can be selected with a full graphical representation of the cluster-associate model (6) after its identification by three reference points in the coordinates $\ln \eta-1 / T$ range from melting point $T_{m}$ to boiling point $T_{b}$ and processed in areas that allow linearization with the inclusion of all experimental values, and with their division into several segments of direct, as well as in the field of lack of experimental data. In all cases, the corresponding values of the activation energy by the Frenkel's equation and the average integral values of the degree of cluster association are found in straight-line segments by formula (13).

Since the value of $\bar{a}$ characterizes the average number of clusters in an associate, then by the ratio $E / \bar{a}$ one can determine the activation energy attributable to the cluster and having the sense of breaking the bond between the cluster and the associate, that is, the beginning of its destruction.

This value should be determined on a wide variety of materials in order to identify any regularities in its change or constancy. Previously, in works [19] [20] [21] [22], it was analyzed on contrast data relating to the viscosity of simple substances and complex slag systems, and in all cases the specific activation energy of a viscous flow, $E / \bar{a}$, did not go beyond the energy of the van der Waals forces [23]. Being the weakest and most unsaturated intermolecular bonds, they are overcome in the first place, which makes it possible to argue about the nature of the viscous flow, which consists in breaking the associates without destroying the clusters that retain the binding energy of the particles in a solid state even with their virtual existence [19] [20] [21].

This paper is devoted to continuing the analysis of the relationship of the cluster-associate model with the Frenkel's viscosity model using the example of the halides of the first group of the Periodic System, for which there are minimally sufficient reference data (at least three experimental values).

\section{Calculations of Viscosity Using the Cluster-Associate Model and the Frenkel's Model}

Lithium chloride. According to the directory [24] found the values $T_{m}=887 \mathrm{~K}$, $T_{b}=1653 \mathrm{~K}$ and three viscosity values used as reference points $T_{1}=910 \mathrm{~K}, \eta_{1}=$ $1.59 \mathrm{mPa} \cdot \mathrm{c} ; T_{2}=980 \mathrm{~K}, \eta_{2}=1.21 \mathrm{mPa} \cdot \mathrm{c} ; T_{3}=1080 \mathrm{~K}, \eta_{3}=0.87 \mathrm{mPa} \cdot \mathrm{c}$. Using them, using Equations ((7), (8)), we have identified the viscosity Equations (6) and the degree of cluster association (5):

$$
\begin{gathered}
\eta=1.59\left(\frac{910}{T}\right)^{3.6853(980 / T)^{0.4703}}, \mathrm{mPa} \cdot \mathrm{c} \\
a=3.6853(980 / T)^{0.4703} .
\end{gathered}
$$

The results of calculations on them with extrapolation to $T_{m}$ and to $T_{b}$ are presented in Table 1 and in Figure 1 and Figure 2.

According to these data, the dynamic viscosity of lithium chloride, as well as the degree of cluster association, regularly decreases with deceleration as it approaches the boiling point. The similar nature of these patterns is the basis for 
Table 1. Reference [24] and calculated by (14) and (15) values of the dynamic viscosity and the degree of association of clusters of liquid lithium chloride.

\begin{tabular}{cccccccc}
\hline$T, \mathrm{~K}$ & $\begin{array}{c}\eta[24], \\
\mathrm{mPa} \cdot \mathrm{c}\end{array}$ & $\begin{array}{c}\eta(14), \\
\mathrm{mPa} \cdot \mathrm{c}\end{array}$ & $a(15)$ & $T, \mathrm{~K}$ & $\begin{array}{c}\eta[24], \\
\mathrm{mPa} \cdot \mathrm{c}\end{array}$ & $\begin{array}{c}\eta(14), \\
\mathrm{mPa} \cdot \mathrm{c}\end{array}$ & $a(15)$ \\
\hline$T_{T}=887$ & - & 1.755 & 3.862 & 1040 & - & 0.985 & 3.584 \\
900 & - & 1.659 & 3.836 & 1060 & - & 0.925 & 3.552 \\
910 & 1.59 & 1.590 & 3.816 & 1080 & 0.87 & 0.870 & 3.521 \\
930 & - & 1.465 & 3.777 & 1180 & - & 0.661 & 3.377 \\
950 & - & 1.354 & 3.740 & 1280 & - & 0.525 & 3.250 \\
970 & - & 1.255 & 3.703 & 1380 & - & 0.431 & 3.137 \\
980 & 1.21 & 1.210 & 3.685 & 1480 & - & 0.363 & 3.036 \\
1000 & - & 1.127 & 3.650 & 1580 & - & 0.313 & 2.944 \\
1020 & - & 1.052 & 3.617 & $T_{b}=1653$ & - & 0.285 & 2.882 \\
\hline
\end{tabular}

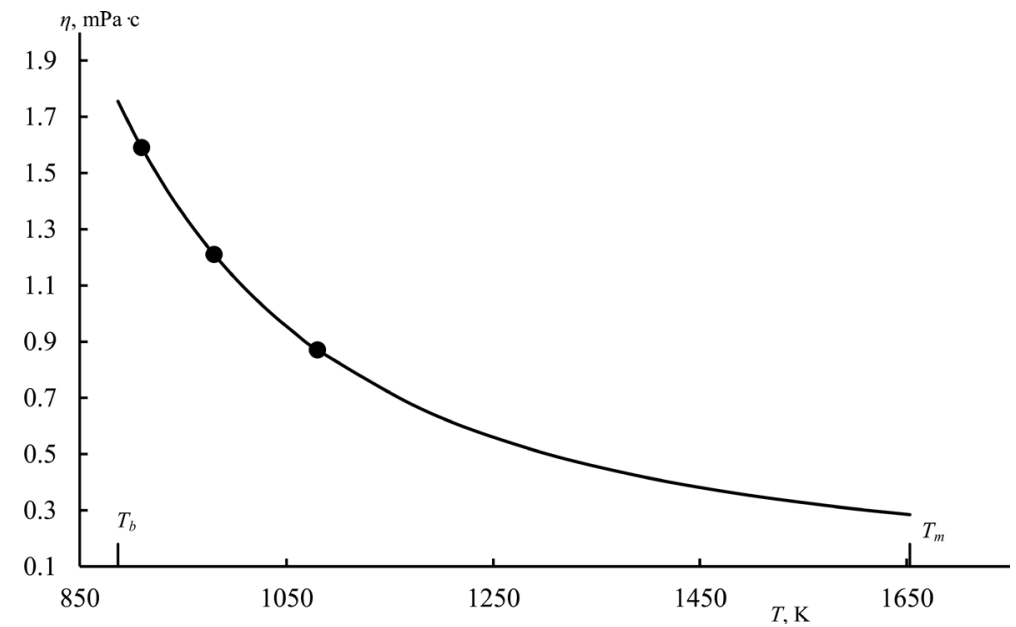

Points-reference data [24], line-by (14).

Figure 1. Dependence of dynamic viscosity of liquid lithium chloride on temperature.

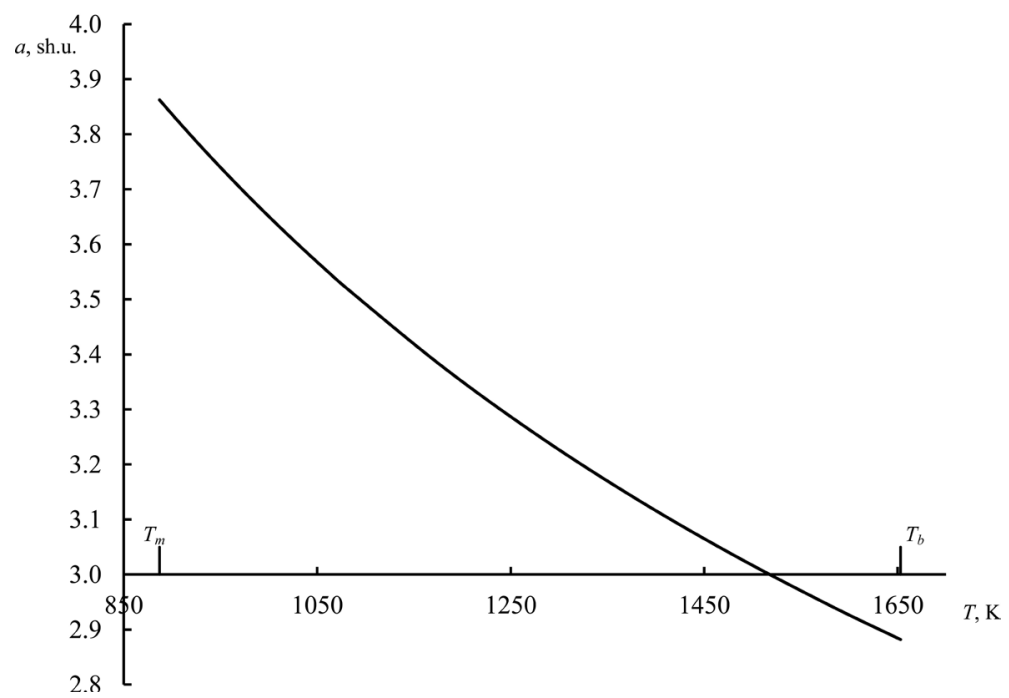

Figure 2. Dependence of the degree of association of clusters in lithium chloride on temperature. 
constructing a cluster-associate viscosity model [19] [20] [21], and this is confirmed by the actual expression of data on $\eta$ and $a$, reflecting both a decrease in the share of clusters and associates with an increase in temperature.

In the $\ln \eta-1 / T$ coordinates, almost straight-line placement of experimental and calculated data is observed over the entire temperature range (Figure 3 ). According to the parameters of the straight-line approximation of these data, the Fraenkel equation is obtained

$$
\eta=3.43 \times 10^{-2} \mathrm{e}^{\frac{29045}{R T}}, \mathrm{mPa} \cdot \mathrm{c},
$$

with the value of the activation energy of fluidity $29,045 \mathrm{~J} / \mathrm{mol}$.

In the framework of the cluster-associate viscosity model, this value refers to a flow unit - cluster association. According to (13), the average integral value of the degree of association of clusters in the range $T_{m}-T_{b}$ is $\bar{a}=3.298$, and then we obtain the ratio $E / \bar{a}=8807 \mathrm{~J} /$ cluster corresponding to the energy of van der Waals attraction of molecules.

Direct comparison of cluster-associate (14) and Frenkel (16) models viscosity is presented in Table 2 .

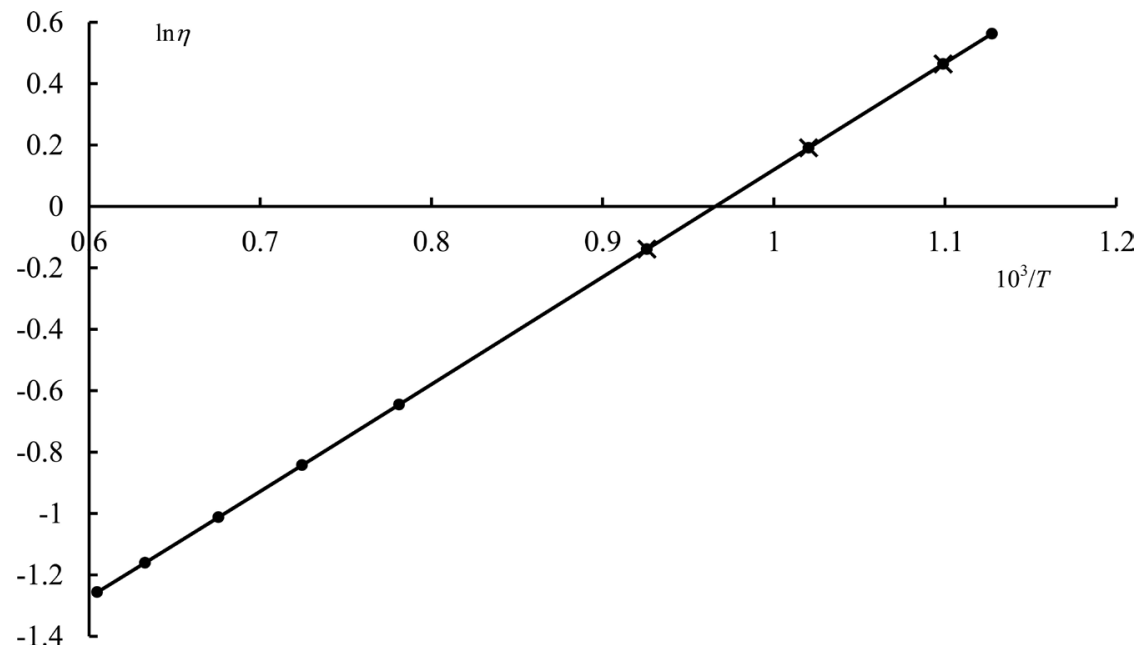

Crosses-by experimental data, points—by logarithmic calculated values (14), line-approximating straight line.

Figure 3. Logarithmic dependence of the viscosity of LiClback temperature.

Table 2. Dynamic viscosity of lithium chloride according to cluster-associate Equation (14) and Frenkel Equation (16).

\begin{tabular}{ccccccccc}
\hline$T, \mathrm{~K}$ & $\begin{array}{c}\eta(14), \\
\mathrm{mPa} \cdot \mathrm{c}\end{array}$ & $\begin{array}{c}\eta(16), \\
\mathrm{mPa} \cdot \mathrm{c}\end{array}$ & $T, \mathrm{~K}$ & $\begin{array}{c}\eta(14), \\
\mathrm{mPa} \cdot \mathrm{c}\end{array}$ & $\begin{array}{c}\eta(16), \\
\mathrm{mPa} \cdot \mathrm{c}\end{array}$ & $T, \mathrm{~K}$ & $\begin{array}{c}\eta(14), \\
\mathrm{mPa} \cdot \mathrm{c}\end{array}$ & $\begin{array}{c}\eta(16), \\
\mathrm{mPa} \cdot \mathrm{c}\end{array}$ \\
\hline$T_{T}=887$ & 1.755 & 1.761 & 980 & 1.210 & 1.212 & 1180 & 0.661 & 0.662 \\
900 & 1.659 & 1.663 & 1000 & 1.127 & 1.128 & 1280 & 0.525 & 0.525 \\
910 & 1.590 & 1.594 & 1020 & 1.052 & 1.054 & 1380 & 0.431 & 0.431 \\
930 & 1.465 & 1.468 & 1040 & 0.985 & 0.986 & 1480 & 0.363 & 0.363 \\
950 & 1.354 & 1.356 & 1060 & 0.925 & 0.926 & 1580 & 0.313 & 0.313 \\
970 & 1.255 & 1.257 & 1080 & 0.870 & 0.871 & $T_{b}=1653$ & 0.285 & 0.284 \\
\hline
\end{tabular}


It is characterized by the correlation coefficient $R=0.99979$ with the significance of the Student coefficient $t_{R}=9641 \gg 2$ and the degree of determination $D=R^{2}=0.99958$, which indicates the functional nature of the relationship of these models, due to their physical, probabilistic and structural conformity.

Sodium chloride. According to the directory [24] found the values $T_{m}=1074$ $\mathrm{K}, T_{b}=1738 \mathrm{~K}$. Of the eight viscosity data presented, three reference points were selected: $T_{1}=1098 \mathrm{~K}, \eta_{1}=1.432 \mathrm{mPa} \cdot \mathrm{c} ; T_{2}=1173 \mathrm{~K}, \eta_{2}=1.017 \mathrm{mPa} \cdot \mathrm{c} ; T_{3}=1273$ $\mathrm{K}, \eta_{3}=0.704 \mathrm{mPa} \cdot \mathrm{c}$. From these data, we obtained the calculated dependences for the viscosity and the degree of cluster association

$$
\begin{gathered}
\eta=1.432\left(\frac{1098}{T}\right)^{5.1792(1173 / T)^{0.9261}}, \mathrm{mPa} \cdot \mathrm{c} \\
a=5.1792(1173 / T)^{0.9261} .
\end{gathered}
$$

The results of calculation on them with extrapolation on $T_{m}$ and up to $T_{b}$ are given in Table 3 and in Figure 4.

The correlation coefficient was $R=0.999026$ at $t_{R}=513 \gg 2$ and $D=0.998$.

In logarithmic coordinates, these data are presented in Figure 5.

Here, the noticeable curvature of the logarithmic dependence (17) forces us to carry out a linear approximation at two ranges with obtaining two Frenkel equations for the ranges $T_{m}-1273$ и $1273-T_{b}$ :

$$
\begin{aligned}
& \eta=6.493 \times 10^{-3} \mathrm{e}^{\frac{49326}{R T}}, \mathrm{mPa} \cdot \mathrm{c} \\
& \eta=2.175 \times 10^{-2} \mathrm{e}^{\frac{36464}{R T}}, \mathrm{mPa} \cdot \mathrm{c}
\end{aligned}
$$

Table 3. Reference [24] and calculated by (17) and (18) values of the dynamic viscosity and the degree of association of clusters of liquid sodium chloride.

\begin{tabular}{ccccccc}
\hline$T, \mathrm{~K}$ & $\eta[24], \mathrm{mPa} \cdot \mathrm{c}$ & $\eta(17), \mathrm{mPa} \cdot \mathrm{c}$ & $a(18)$ & $T, \mathrm{~K}$ & $\eta(17), \mathrm{mPa} \cdot \mathrm{c}$ & $a(18)$ \\
\hline$T_{m}=1074$ & - & 1.621 & 5.620 & 1423 & 0.466 & 4.331 \\
1098 & 1.432 & 1.432 & 5.506 & 1448 & 0.440 & 4.261 \\
1123 & 1.275 & 1.268 & 5.393 & 1473 & 0.419 & 4.194 \\
1148 & 1.138 & 1.132 & 5.284 & 1498 & 0.397 & 4.130 \\
1173 & 1.017 & 1.017 & 5.179 & 1523 & 0.379 & 4.067 \\
1198 & 0.912 & 0.920 & 5.079 & 1548 & 0.362 & 4.006 \\
1223 & 0.82 & 0.837 & 4.983 & 1573 & 0.347 & 3.947 \\
1248 & 0.752 & 0.766 & 4.890 & 1598 & 0.333 & 3.890 \\
1273 & 0.704 & 0.704 & 4.801 & 1623 & 0.320 & 3.834 \\
1298 & - & 0.651 & 4.716 & 1648 & 0.309 & 3.780 \\
1323 & - & 0.604 & 4.633 & 1673 & 0.298 & 3.728 \\
1348 & - & 0.563 & 4.553 & 1698 & 0.288 & 3.677 \\
1373 & - & 0.527 & 4.477 & 1723 & 0.279 & 3.628 \\
1398 & - & 0.494 & 4.402 & $T_{b}=1738$ & 0.274 & 3.599 \\
\hline
\end{tabular}




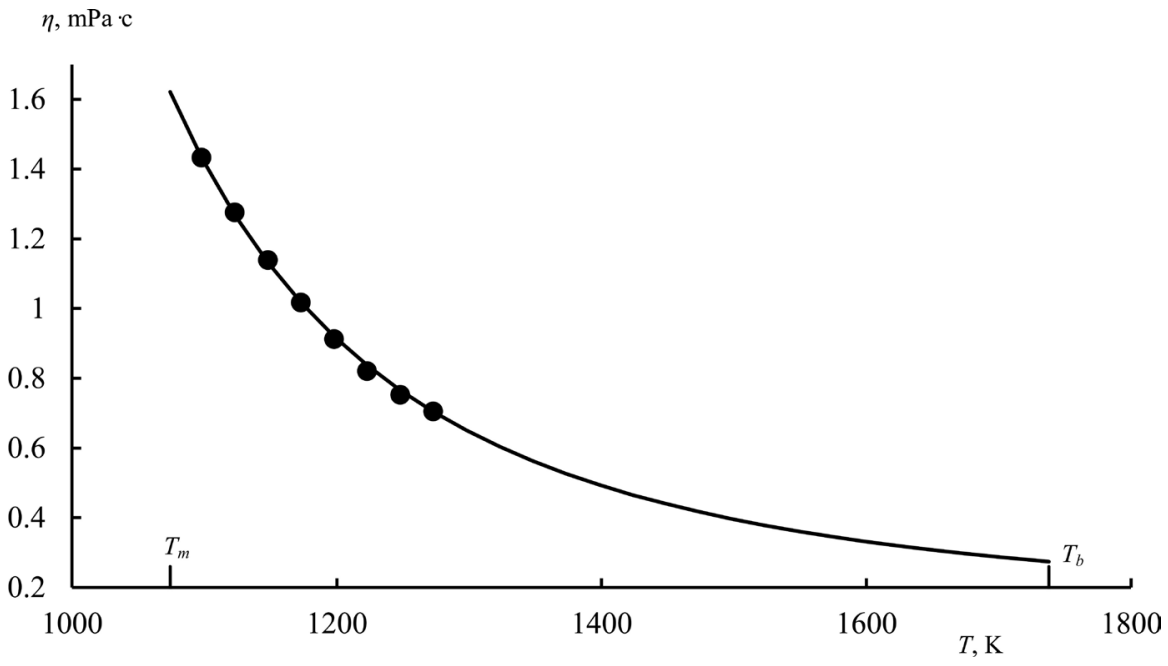

Points-reference data [24], line-by (17).

Figure 4. Dependence of dynamic viscosity of liquid sodium chloride on temperature.

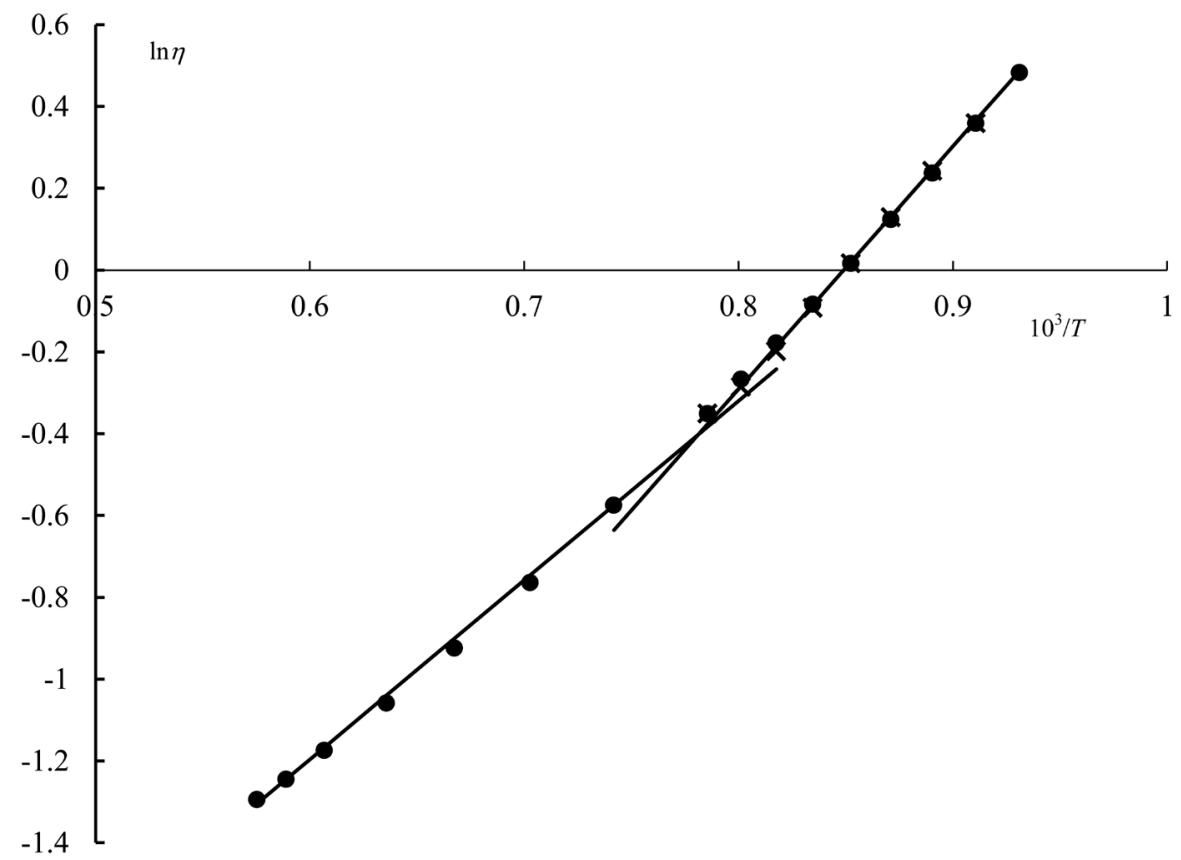

Crosses-by experimental data [24], points-according to calculated from Table 3, straight lines-approximation by the Frenkel equation.

Figure 5. Logarithmic dependence of the viscosity of $\mathrm{NaCl}$ on the inverse temperature.

with the corresponding values of the activation energy of fluidity 49,326 and $36,464 \mathrm{~J} / \mathrm{mol}$. For the same ranges, the average integral values of the degree of cluster association were 5.193 and 3.94, and the values of $E / \bar{a}$ are 9499 and $9255 \mathrm{~J} /$ cluster, respectively, which are close in size and are within the van der Waals energy of the intermolecular attraction of molecules. The correlation coefficient of the Frenkel Equation (19) with respect to the reference data turned out to be close to unity, as well as of both the Frenkel Equations (19) and (20) with respect to the cluster-associate model (17). 
Potassium chloride. Reference [24] contains the values $T_{m}=1049 \mathrm{~K}, T_{b}=1773$ $\mathrm{K}$, as well as information on the four viscosity values, of which they were chosen as reference points $T_{1}=1063 \mathrm{~K}, \eta_{1}=1.42 \mathrm{mPa} \cdot \mathrm{c} ; T_{2}=1108 \mathrm{~K}, \eta_{2}=1.21 \mathrm{mPa} \cdot \mathrm{c} ; T_{3}$ $=1308 \mathrm{~K}, \eta_{3}=0.71 \mathrm{mPa} \cdot \mathrm{c}$. With their help, found the parameters of a cluster-associate model of potassium chloride

$$
\begin{gathered}
\eta=1.42\left(\frac{1063}{T}\right)^{3.860(1108 / T)^{0.8682}}, \mathrm{mPa} \cdot \mathrm{c} \\
a=3.860(1108 / T)^{0.8682} .
\end{gathered}
$$

The calculation results for them are presented in Table 4 and in Figure 6.

According to these data, a regular, with a slowdown, a decrease in the viscosity and degree of association of clusters with an increase in temperature is observed.

Table 4. Reference [24] and calculated by (21) and (22) values of the dynamic viscosity and the degree of association of clusters of liquid potassium chloride.

\begin{tabular}{ccccccc}
\hline$T, \mathrm{~K}$ & $\eta[24], \mathrm{mPa} \cdot \mathrm{c}$ & $\eta(21), \mathrm{mPa} \cdot \mathrm{c}$ & $a(22)$ & $T, \mathrm{~K}$ & $\eta(21), \mathrm{mPa} \cdot \mathrm{c}$ & $a(22)$ \\
\hline$T_{m}=1049$ & - & 1.498 & 4.048 & 1400 & 0.596 & 3.151 \\
1063 & 1.42 & 1.420 & 4.001 & 1450 & 0.550 & 3.056 \\
1108 & 1.21 & 1.210 & 3.860 & 1500 & 0.511 & 2.967 \\
1150 & - & 1.058 & 3.737 & 1550 & 0.479 & 2.884 \\
1193 & 0.99 & 0.935 & 3.620 & 1600 & 0.451 & 2.806 \\
1200 & - & 0.918 & 3.602 & 1650 & 0.427 & 2.732 \\
1250 & - & 0.808 & 3.476 & 1700 & 0.407 & 2.662 \\
1300 & - & 0.722 & 3.360 & 1750 & 0.389 & 2.596 \\
1308 & 0.71 & 0.710 & 3.342 & $T_{b}=1773$ & 0.382 & 2.566 \\
1350 & - & 0.653 & 3.252 & & & \\
\hline
\end{tabular}

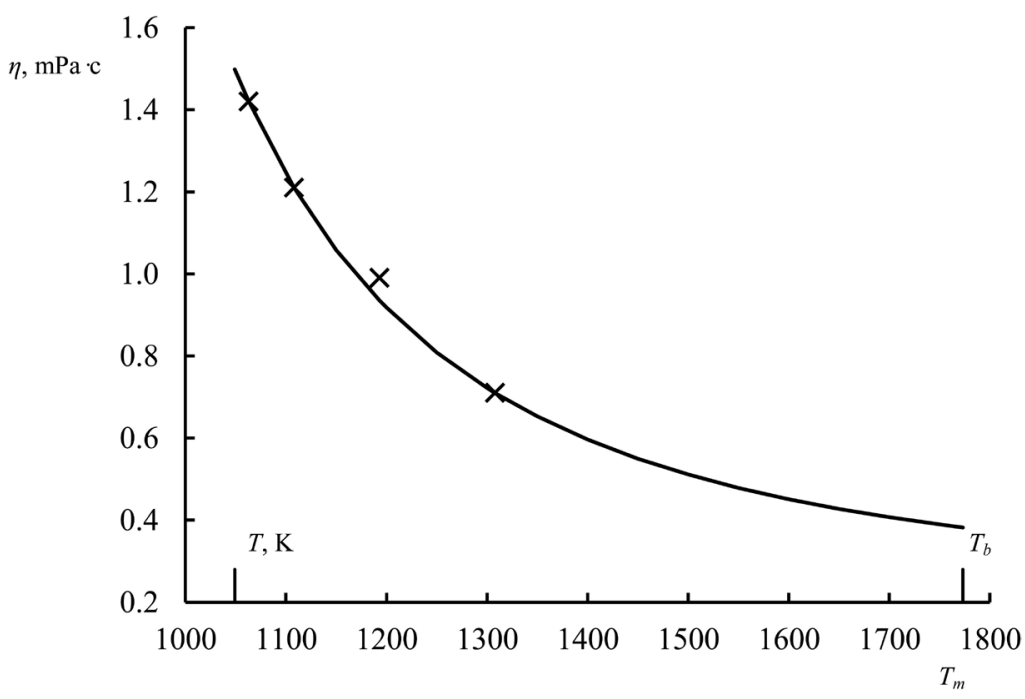

Points-reference data [24], line-by (21).

Figure 6. Dependence of dynamic viscosity of liquid potassium chloride on temperature. 
The correlation coefficient with reference values was $R=0.992$ at $t_{R}=122>2$ and $D=0.984$.

In logarithmic coordinates, the temperature dependence of the viscosity of potassium chloride is shown in Figure 7.

Here a linear approximation is possible in the whole range of the liquid state of potassium chloride,

$$
\eta=5.5 \times 10^{-2} \mathrm{e}^{\frac{28546}{R T}}, \mathrm{mPa} \cdot \mathrm{c}
$$

The correlation coefficient with the experimental data was $R=0.973$ at $t_{R}=$ $36.3>2$ and $D=0.947$, and with cluster-associate Equation (21) $R=0.9779$ at $t_{R}$ $=374>2$ and $D=0.9889$, indicating a fairly close functional relationship.

The average integral value of the degree of cluster association in the full range of the liquid state of potassium chloride is $\bar{a}=3.187$, that in comparison with the activation energy of fluidity $E=28,546 \mathrm{~J} / \mathrm{mol}$ gives the ratio $E / \bar{a}=8957$ $\mathrm{J} /$ cluster, newly located within the energy of van der Waals attraction.

Silver chloride. Reference [24] lists $T_{m}=728 \mathrm{~K}, T_{b}=1823 \mathrm{~K}$ and contains viscosity information for three temperatures $T_{1}=730 \mathrm{~K}, \eta_{1}=2.29 \mathrm{mPa} \cdot \mathrm{c} ; T_{2}=850$ $\mathrm{K}, \eta_{2}=1.74 \mathrm{mPa} \cdot \mathrm{c} ; T_{3}=970 \mathrm{~K}, \eta_{3}=1.41 \mathrm{mPa} \cdot \mathrm{c}$, which were chosen as reference points for building a cluster-associate model

$$
\begin{gathered}
\eta=2.29\left(\frac{730}{T}\right)^{1.8047(850 / T)^{0.4256}}, \mathrm{mPa} \cdot \mathrm{c} \\
a=1.8047(850 / T)^{0.4256} .
\end{gathered}
$$

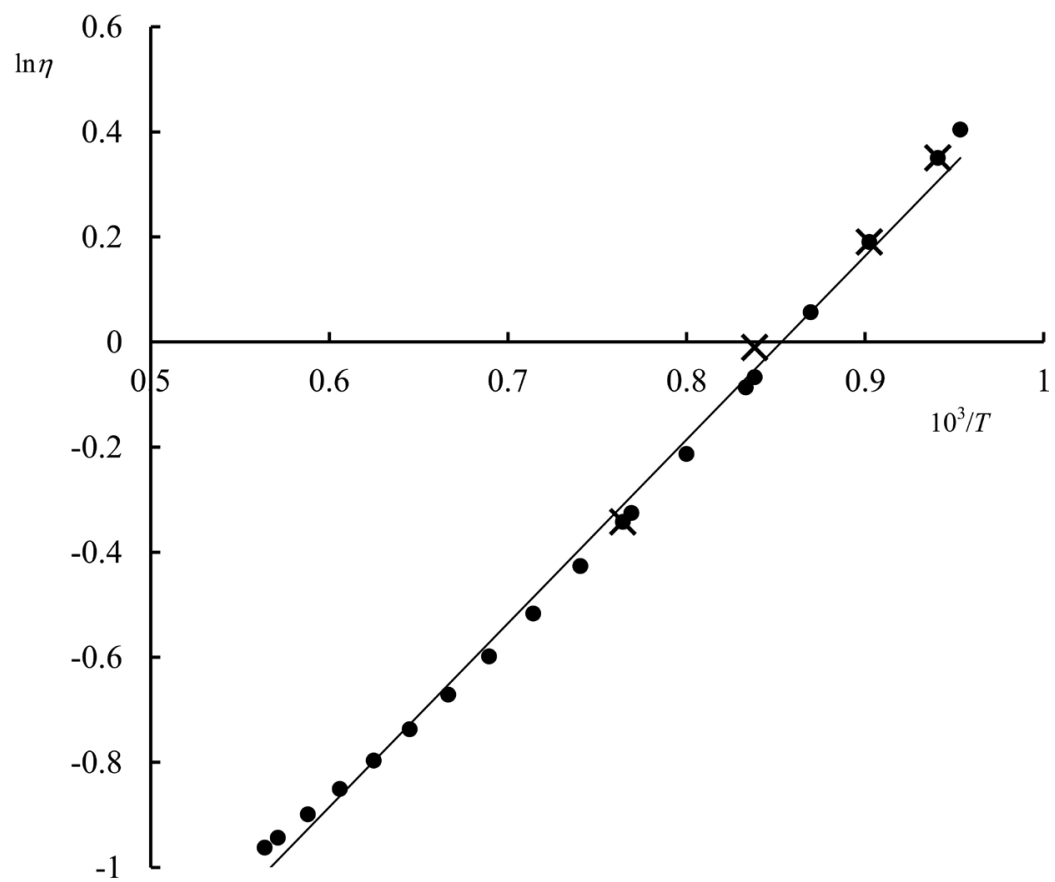

Crosses-by experimental data [24], points-according to calculated from Table 4, straight lines-approximation by the Frenkel equation.

Figure 7. Logarithmic dependence of the viscosity of $\mathrm{KCl}$ on the inverse temperature. 
The calculation results for these equations are given in Table 5 and in Figure 8.

They testify to the preservation of the monotonous nature of the loss of both dependencies, and in logarithmic coordinates (Figure 9) there is an almost straightforward placement of reference and calculated data. They obtained the Fraenkel equation for silver chloride

$$
\eta=0.317 \times 10^{-2} \mathrm{e}^{\frac{12039}{R T}}, \mathrm{mPa} \cdot \mathrm{c}
$$

The correlation coefficient with reference data was $R=0.9995$ at $t_{R}=992 \gg 2$ and $D=0.999$.

Comparison of calculated values for (26) with (24) is characterized by $R=$ 0.999907 at $t_{R}=21423 \gg 2$ and $D=0.9998$, which indicates the functional proximity of cluster-associate and molecular-kinetic viscosity models.

Table 5. Reference [24] and calculated by (24) values of the dynamic viscosity and the degree of association of clusters (25) of liquid silver chloride.

\begin{tabular}{ccccccc}
\hline$T, \mathrm{~K}$ & $\eta[24], \mathrm{mPa} \cdot \mathrm{c}$ & $\eta(24), \mathrm{mPa} \cdot \mathrm{c}$ & $a(25)$ & $T, \mathrm{~K}$ & $\eta(24), \mathrm{mPa} \cdot \mathrm{c}$ & $a(25)$ \\
\hline$T_{m}=728$ & - & 2.302 & 1.928 & 1100 & 1.180 & 1.617 \\
730 & 2.29 & 2.290 & 1.926 & 1200 & 1.056 & 1.558 \\
750 & - & 2.175 & 1.904 & 1300 & 0.960 & 1.506 \\
800 & - & 1.933 & 1.852 & 1400 & 0.885 & 1.459 \\
850 & 1.74 & 1.740 & 1.805 & 1500 & 0.825 & 1.417 \\
900 & - & 1.584 & 1.761 & 1600 & 0.776 & 1.379 \\
950 & - & 1.455 & 1.721 & 1700 & 0.735 & 1.344 \\
970 & 1.41 & 1.410 & 1.706 & 1800 & 0.701 & 1.311 \\
1000 & - & 1.348 & 1.684 & $T_{b}=1823$ & 0.694 & 1.304 \\
\hline
\end{tabular}

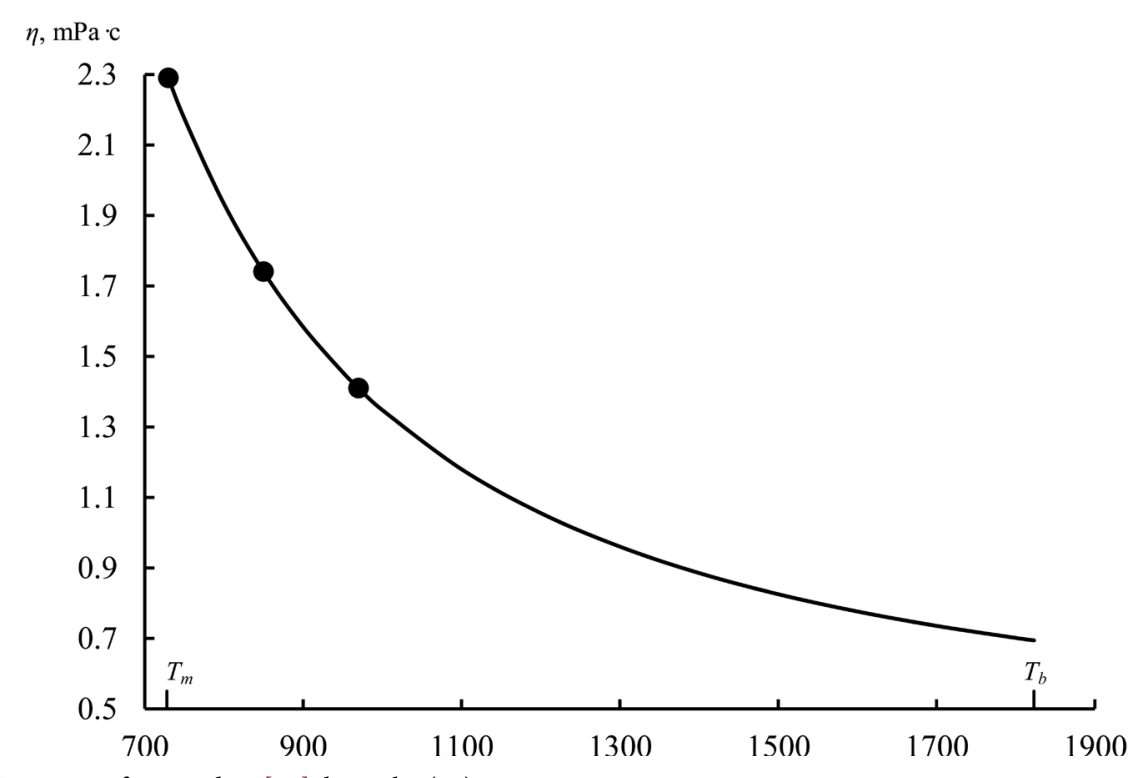

Points-reference data [24], line-by (24).

Figure 8. Dependence of dynamic viscosity of liquid silver chloride on temperature. 


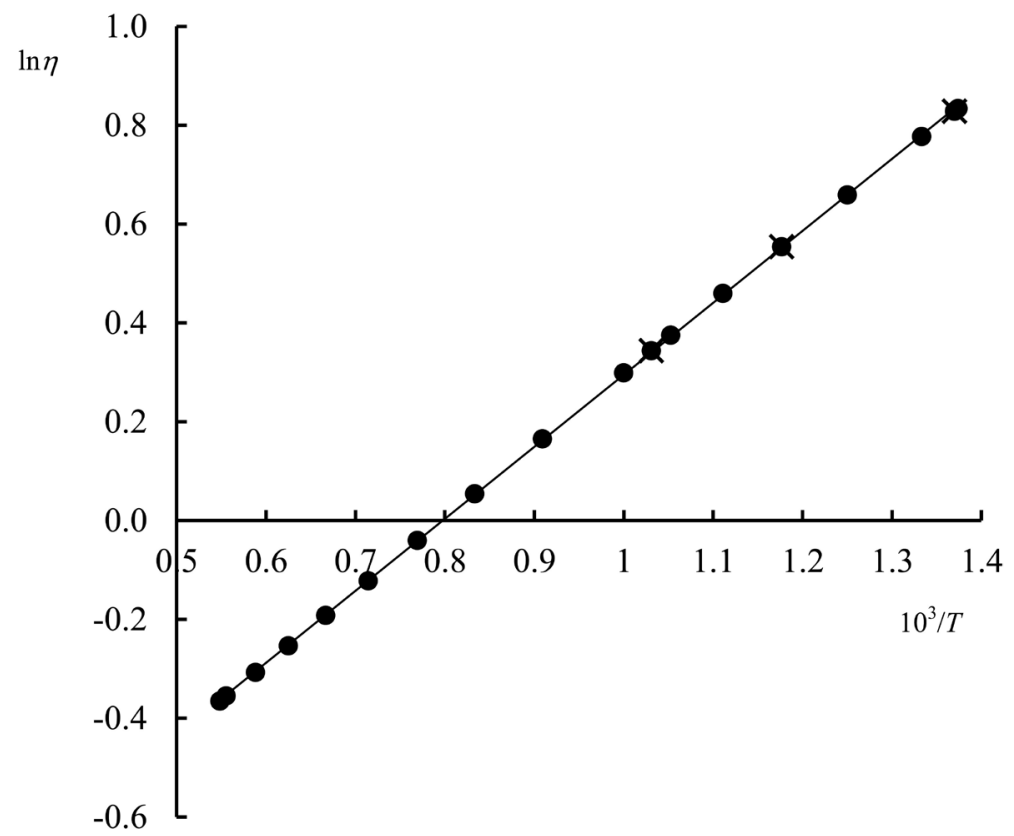

Crosses-by experimental data [24], points-according to calculated from Table 5, straight lines-approximation by the Frenkel equation.

Figure 9. Logarithmic dependence of the viscosity of $\mathrm{AgCl}$ on the inverse temperature.

Their mutual complementarity is indicated by the consistency of the activation energy flow of $12,039 \mathrm{~J} / \mathrm{mol}$ and the average integral degree of cluster association $\bar{a}=1.549$, giving, at their $E / \bar{a}$ ratio, a value of $7772 \mathrm{~J} /$ cluster, which is in the intermolecular energy interval.

Sodium fluoride. According to the reference [24] found the values $T_{m}=1265$ K и $T_{b}=1973 \mathrm{~K}$, as well as three viscosity values that were used as reference points: $T_{1}=1288 \mathrm{~K}, \eta_{1}=1.85 \mathrm{mPa} \cdot c ; T_{2}=1383 \mathrm{~K}, \eta_{2}=1.41 \mathrm{mPa} \cdot c ; T_{3}=1473 \mathrm{~K}$, $\eta_{3}=1.14 \mathrm{mPa} \cdot \mathrm{c}$. They determined the parameters of the cluster-associate model for liquid sodium fluoride

$$
\begin{gathered}
\eta=1.85\left(\frac{1288}{T}\right)^{3.816(1383 / T)^{0.893}}, \mathrm{mPa} \cdot \mathrm{c} \\
a=3.816(1383 / T)^{0.893} .
\end{gathered}
$$

The results of the calculation in the full range of the liquid state are given in Table 6 and in Figure 10.

A simbatic decrease with a slowing down of the viscosity and the degree of association of clusters in this case in the coordinates $\ln \eta-1 / T$ leads to a noticeably curvilinear placement of the data in Table 6.

This forces us to carry out a linear approximation at two ranges, $T_{m}-1500$ and 1500- $T_{b}$, with obtaining two Frenkel equations (Figure 11)

$$
\begin{aligned}
& \eta=4.416 \times 10^{-2} \mathrm{e}^{\frac{39909}{R T}}, \mathrm{mPa} \cdot \mathrm{c} \\
& \eta=7.746 \times 10^{-2} \mathrm{e}^{\frac{32592}{R T}}, \mathrm{mPa} \cdot \mathrm{c}
\end{aligned}
$$


Table 6. Reference [24] and calculated by (27) and (28) values of the dynamic viscosity and the degree of association of clusters of liquid sodium fluoride.

\begin{tabular}{ccccccc}
\hline$T, \mathrm{~K}$ & $\eta[24], \mathrm{mPa} \cdot \mathrm{c}$ & $\eta(27), \mathrm{mPa} \cdot \mathrm{c}$ & $a(28)$ & $T, \mathrm{~K}$ & $\eta(27), \mathrm{mPa} \cdot \mathrm{c}$ & $a(28)$ \\
\hline$T_{m}=1265$ & - & 1.993 & 4.133 & 1600 & 0.894 & 3.351 \\
1288 & 1.85 & 1.850 & 4.067 & 1650 & 0.825 & 3.260 \\
1300 & - & 1.782 & 4.033 & 1700 & 0.767 & 3.174 \\
1350 & - & 1.540 & 3.900 & 1750 & 0.717 & 3.093 \\
1383 & 1.41 & 1.410 & 3.817 & 1800 & 0.674 & 3.016 \\
1400 & - & 1.350 & 3.775 & 1850 & 0.637 & 2.943 \\
1450 & - & 1.199 & 3.659 & 1900 & 0.605 & 2.874 \\
1473 & 1.14 & 1.140 & 3.607 & 1950 & 0.577 & 2.808 \\
1500 & - & 1.077 & 3.549 & $T_{b}=1973$ & 0.566 & 2.779 \\
1550 & - & 0.977 & 3.447 & & & \\
\hline
\end{tabular}

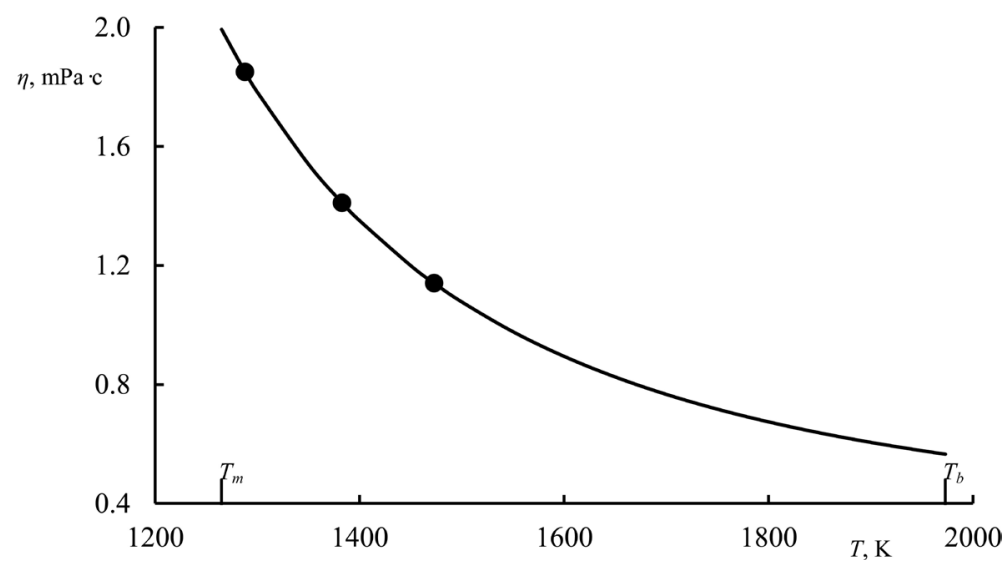

Points-reference data [24], line-by (27).

Figure 10. Dependence of dynamic viscosity of liquid sodium fluoride on temperature.

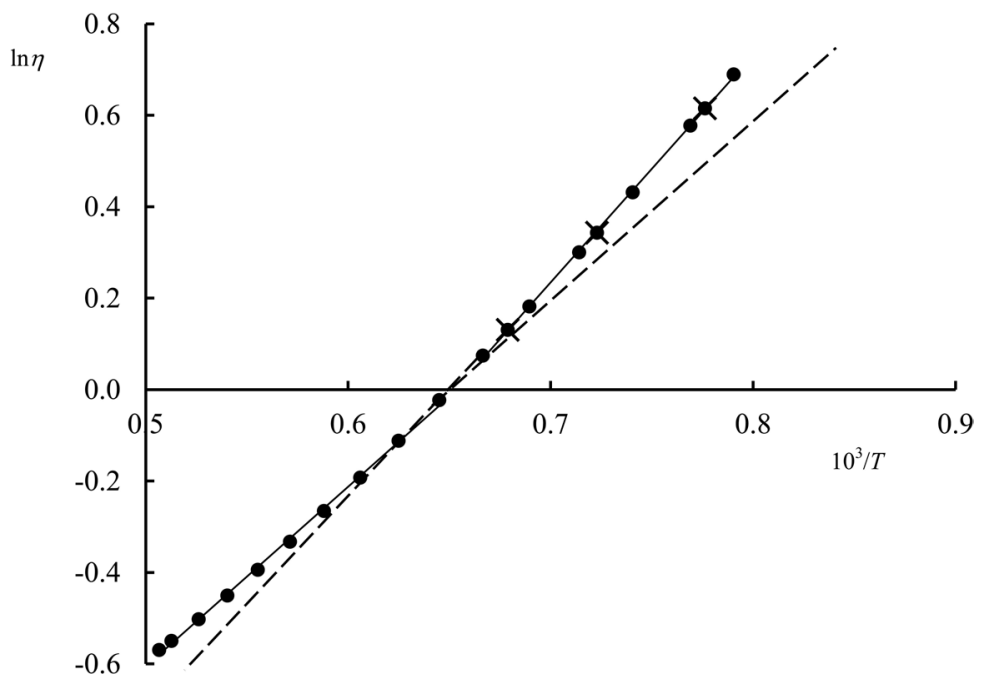

Crosses-by experimental data [24], points-according to cluster-associate model (29), solid straight lines-approximation by the Frenkel model, dashed lines-extrapolation to another temperature range.

Figure 11. Logarithmic dependence of the viscosity of $\mathrm{NaF}$ on the inverse temperature. 
From Figure 11 it is noticeable that extrapolation of the Frenkel equation beyond the limits of linearized areas leads to deviations from the cluster-associate model (27) that is uniform for the entire range, reaching $11 \%-14 \%$ at the extrapolation limits. At the same time, within the linearized areas, the correlation coefficient with the cluster-associate model was $R=0.99968$ at $t_{R}=6382 \gg 2$ and $D=0.99935$, pointing to the functional relationship of both models. This relationship is reinforced by their physical interdependence through the ratio $E / \bar{a}$ which for the low temperature range is $39,909 / 3.825=$ $10,433 \mathrm{~J} /$ cluster, and for high temperature-32,592/3.131 $=10,409 \mathrm{~J} /$ cluster, almost identical values, a kind of intercluster bonds invariant in associates at the level of van der Waals attraction energy, or rupture during viscous flow.

Potassium iodide. According to it in [24] contains information about $T_{m}=$ $959 \mathrm{~K}$ and $T_{b}=1593 \mathrm{~K}$, as well as three viscosity values that were chosen as reference points: $T_{1}=980 \mathrm{~K}, \eta_{1}=1.53 \mathrm{mPa} \cdot \mathrm{c}, T_{2}=1080 \mathrm{~K}, \eta_{2}=1.19 \mathrm{mPa} \cdot \mathrm{c}, T_{3}=$ $1160 \mathrm{~K}, \eta_{3}=1.00 \mathrm{mPa} \cdot \mathrm{c}$. They are used to build a cluster-associate viscosity model $K I$

$$
\begin{gathered}
\eta=1.53\left(\frac{980}{T}\right)^{2.587(1080 / T)^{0.353}}, \mathrm{mPa} \cdot \mathrm{C} \\
a=2.587(1080 / T)^{0.353} .
\end{gathered}
$$

The calculation results for them are shown in Table 7 and in Figure 12.

In logarithmic coordinates, these data are presented in Figure 13. Judging from the figure, the calculated and reference data are approximated to a straight line in the full range of the liquid state of potassium iodide, which makes it possible to describe the full range with a single Frenkel equation:

$$
\eta=8.892 \times 10^{-2} \mathrm{e}^{\frac{23280}{R T}}, \mathrm{mPa} \cdot \mathrm{c}
$$

The correlation coefficient of models (31) and (33) was $R=0.99955$ at $t_{R}=3161 \gg 2$

Table 7. Reference [24] and calculated by (31) and (32) values of the dynamic viscosity and the degree of association of clusters of liquid potassium iodide.

\begin{tabular}{cccc}
\hline$T, \mathrm{~K}$ & $\eta[24], \mathrm{mPa} \cdot \mathrm{c}$ & $\eta(31), \mathrm{mPa} \cdot \mathrm{c}$ & $a(32)$ \\
\hline$T_{m}=959$ & - & 1.622 & 2.697 \\
980 & 1.53 & 1.530 & 2.677 \\
1080 & 1.19 & 1.190 & 2.587 \\
1160 & 1.00 & 1.000 & 2.522 \\
1240 & - & 0.857 & 2.463 \\
1320 & - & 0.747 & 2.409 \\
1400 & - & 0.659 & 2.360 \\
1480 & - & 0.589 & 2.314 \\
1560 & - & 0.532 & 2.271 \\
$T_{b}=1593$ & - & 0.512 & 2.255 \\
\hline
\end{tabular}




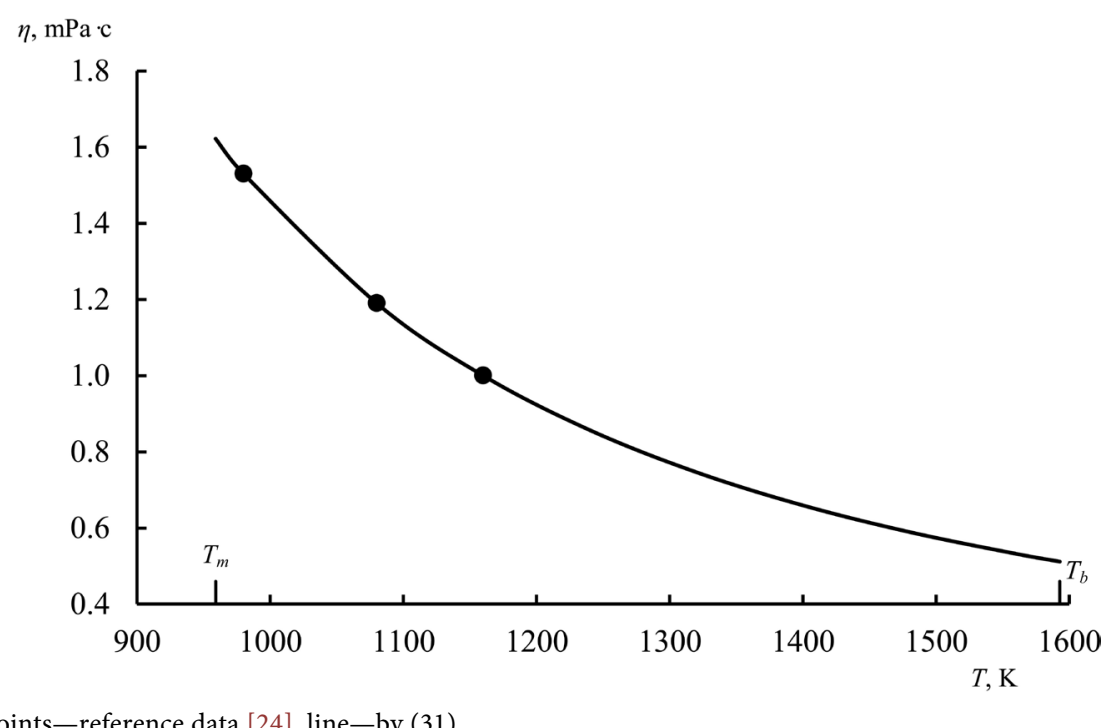

Points-reference data [24], line-by (31)

Figure 12. Dependence of dynamic viscosity of liquid potassium iodide on temperature.

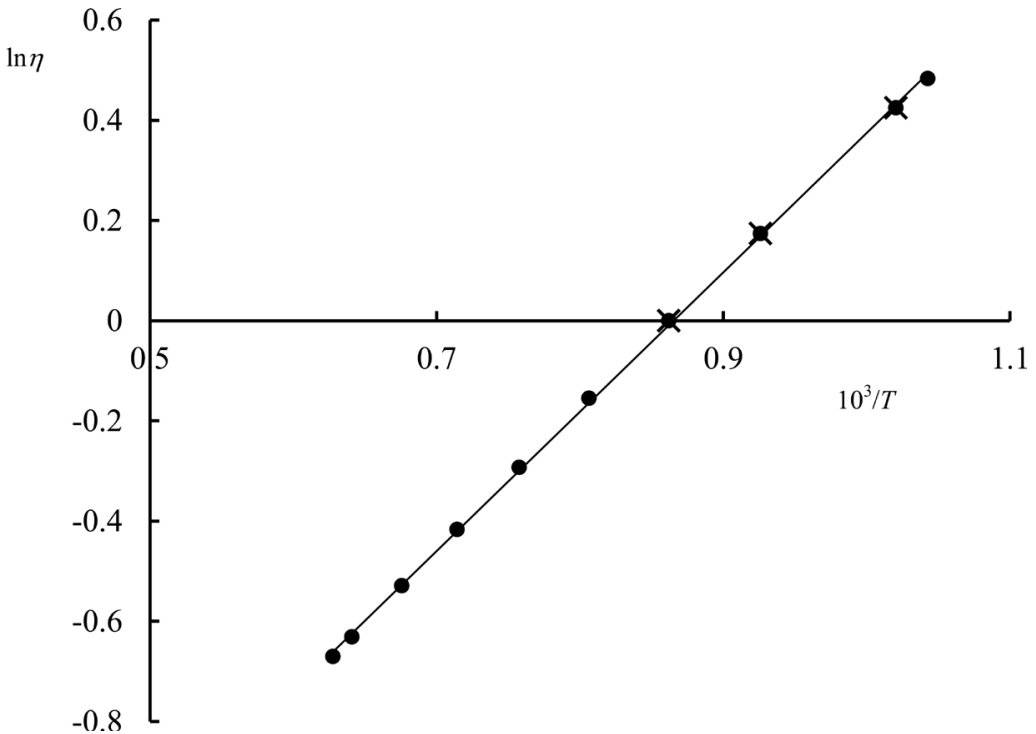

Crosses-by experimental data [24], points-according to cluster-associate model (31), straight line-approximation by Frenkel model.

Figure 13. Logarithmic dependence of the viscosity of potassium iodide on the inverse temperature.

and degree of determination $D=0.99911$. Ratio $E / \bar{a}=23280 / 2.451=9498$ $\mathrm{J} /$ cluster characterizes the energy of the intercluster bond in the associate at the level of the energy of van der Waals attraction.

\section{Discussion and Synthesis of Results}

From Table 8 it follows that with all the variety of halides (chlorides, fluorides, iodides) for the elements of the main and secondary subgroups of the first group of the Periodic System, which is accompanied by a variation in the activation energy of yield in a wide range, from 12,039 to $49,326 \mathrm{~J} / \mathrm{mol}$ and the average 
Table 8. Characteristics of cluster-associate $\left(\eta_{1}\right)$ and Frenkel $\left(\eta_{2}\right)$ viscosity models.

\begin{tabular}{|c|c|c|c|c|c|c|}
\hline Subs-tance & $\begin{array}{c}\text { Temperature } \\
\text { range, } \mathrm{K}\end{array}$ & $\eta_{1}$ and $\eta_{2}, \mathrm{mPa} \cdot \mathrm{c}$ & $E, \mathrm{~J} / \mathrm{mol}$ & $\bar{a}$, sh.u. & $\begin{array}{c}E / \bar{a}, \\
\text { J/cluster }\end{array}$ & $\begin{array}{l}E(34) \\
\mathrm{J} / \mathrm{mol}\end{array}$ \\
\hline $\mathrm{LiCl}$ & $T_{T}-T_{b}$ & $\begin{array}{c}\eta_{1}=1.59(910 / T)^{a} \\
a=3.6853(980 / T)^{0.4703} \\
\eta_{2}=3.43 \times 10^{-2} \mathrm{e}^{\frac{29045}{R T}}\end{array}$ & 29,045 & 3.298 & 8807 & 31,176 \\
\hline \multirow[b]{2}{*}{$\mathrm{NaCl}$} & $T_{T}-1273$ & $\begin{array}{c}\eta_{1}=1.432(1098 / T)^{a} \\
a=5.1792(1173 / T)^{0.9261}\end{array}$ & & & & \\
\hline & $1273-T_{b}$ & $\begin{array}{l}\eta_{2}=6.493 \times 10^{-3} \mathrm{e}^{\frac{49326}{R T}} \\
\eta_{2}=2.175 \times 10^{-2} \mathrm{e}^{\frac{36464}{R T}}\end{array}$ & $\begin{array}{l}49,326 \\
36,464\end{array}$ & $\begin{array}{c}5.193 \\
3.94\end{array}$ & $\begin{array}{l}9499 \\
9255\end{array}$ & $\begin{array}{l}49,089 \\
37,245\end{array}$ \\
\hline$K C l$ & $T_{T}-T_{b}$ & $\begin{array}{c}\eta_{1}=1.42(1063 / T)^{a} \\
a=3.860(1108 / T)^{0.8682} \\
\eta_{2}=5.5 \times 10^{-2} \mathrm{e}^{\frac{28546}{R T}}\end{array}$ & 28,546 & 3.187 & 8957 & 30,127 \\
\hline$A g C l$ & $T_{T}-T_{b}$ & $\begin{array}{c}\eta_{1}=2.29(730 / T)^{a} \\
a=1.8047(850 / T)^{0.4256} \\
\eta_{2}=0.317 \times 10^{-2} \mathrm{e}^{\frac{12039}{R T}}\end{array}$ & 12,039 & 1.549 & 7772 & 14,643 \\
\hline \multirow[b]{2}{*}{$\mathrm{NaF}$} & $T_{T}-1500$ & $\begin{array}{c}\eta_{1}=1.85(1288 / T)^{a} \\
a=3.816(1383 / T)^{0.893}\end{array}$ & & & & \\
\hline & $1500-T_{b}$ & $\begin{array}{l}\eta_{2}=4.416 \times 10^{-2} \mathrm{e}^{\frac{39909}{R T}} \\
\eta_{2}=7.746 \times 10^{-2} \mathrm{e}^{\frac{32592}{R T}}\end{array}$ & $\begin{array}{l}39,909 \\
32,592\end{array}$ & $\begin{array}{l}3.825 \\
3.131\end{array}$ & $\begin{array}{l}10,433 \\
10,409\end{array}$ & $\begin{array}{l}36,158 \\
29,597\end{array}$ \\
\hline$K I$ & $T_{T}-T_{b}$ & $\begin{array}{c}\eta_{1}=1.53(980 / T)^{a} \\
a=2.587(1080 / T)^{0.353} \\
\eta_{2}=8.892 \times 10^{-2} \mathrm{e}^{\frac{23280}{R T}}\end{array}$ & 23,280 & 2.451 & 9498 & 23,169 \\
\hline The average & - & - & 31,400 & 3.322 & 9329 & $(31,403)$ \\
\hline
\end{tabular}

integral degree of cluster association, from 1.549 to 5.193, their ratio remains relatively stable, from 7772 to $10,433 \mathrm{~J} /$ cluster, averaging $9329 \mathrm{~J} / \mathrm{cluster}$ and not going beyond the energy of van der Waals attraction of molecules. This indicates a possible proportional dependence of $E$ on $\bar{a}$, which is traced in Figure 14.

This dependence is constructed from the origin of coordinates, since the absence of clusters in the associate $(\bar{a}=0)$ is possible only at zero activation energy of yield within the cluster-associate model.

The result is the desired dependency

$$
E=9453 \bar{a}, \mathrm{~J} / \mathrm{mol}
$$

correlation coefficient $R=0.9747$ at $t_{R}=47.7>2$ and degree of determination $D$ $=0.95$, evidence of the closeness of this dependence to the functional. According to it, it is possible within the cluster-associate model to estimate the activation energy of fluidity in any temperature range that allows linearization of the results 


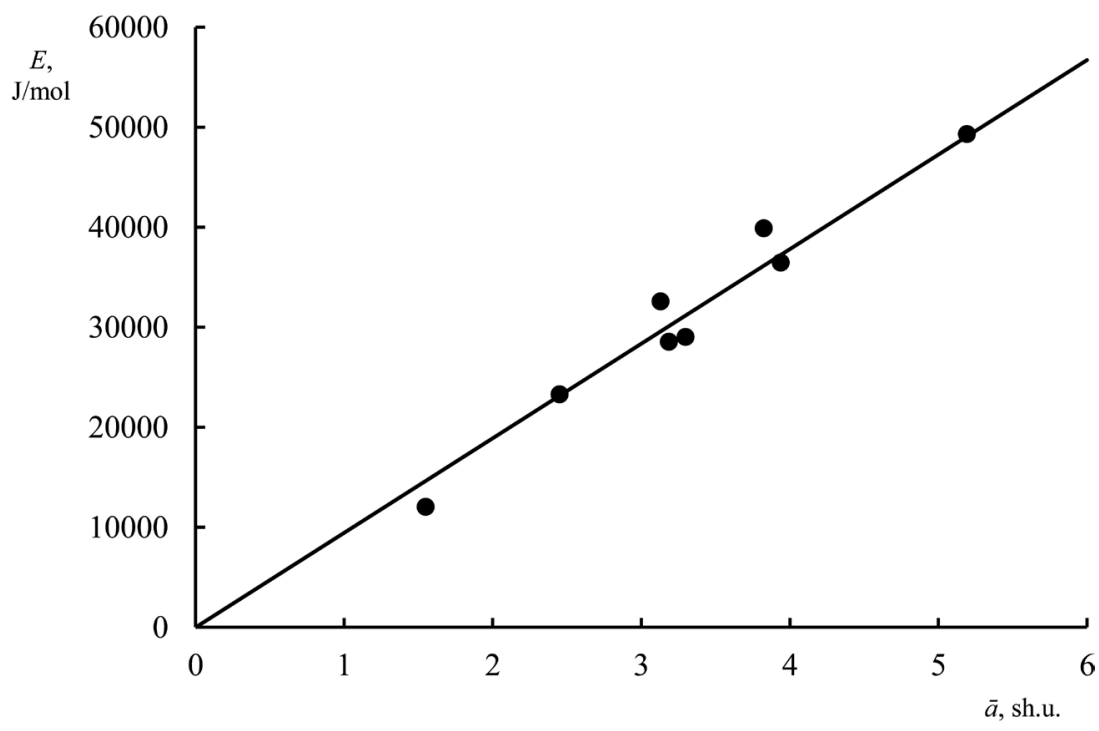

Points-the data of Table 8, the line-according to Equation (34).

Figure 14. Dependence of the activation energy of fluidity on the average integral degree of cluster association.

of the viscosity calculation in coordinates $\ln \eta-1 / T$.

\section{Acknowledgements}

The work was performed in the framework of the project AP05130844/GF on grant funding from the MES Republic of Kazakhstan.

\section{Funding}

The work was carried out as part of the grant project No. AP05130844/GF4 of the Ministry of Education and Science of the Republic of Kazakhstan.

\section{Conflicts of Interest}

The authors declare no conflicts of interest regarding the publication of this paper.

\section{References}

[1] Melikhov, I.V. (2006) Physico-Chemical Evolution of Solids. BINOM, Knowledge Lab, Moscow, $309 \mathrm{p}$.

[2] Elansky, G.N. and Elansky, D.G. (2006) Structure and Properties of Metal Melts. MGBMI, Moscow, 228 p.

[3] Baum, B.A. (1979) Metallic Liquids. Nauka, Moscow, 120 p.

[4] Baum, B.A., Tyagunov, G.V., Baryshev, E.E. and Tsepelev, E.S. (2002) Fundamental Studies of the Physics and Chemistry of Metal Melts. IKC Academcniga, Moscow, $469 \mathrm{p}$.

[5] Gavrilin, I.V. (2000) Melting and Crystallization of Metals and Alloys. VGU, Vladimir, $260 \mathrm{p}$.

[6] Zborshchik, A.M. (2008) Theoretical Foundations of Metallurgical Production. 
GVUZ DonNTU, Donetsk, 189 p.

[7] Lyakishev, N.P. (2002) Fundamental Studies of the Physicochemistry of Metallic Melts. Academcniga, Moscow, $467 \mathrm{p}$.

[8] Cherepakhin, A.A., Koltunov, I.I. and Kuznetsov, V.A. (2009) Materials Science. Knorus, Moscow, 235 p.

[9] Maksimov, A. (2014) New Interpretation in Thermodynamics. Academic Publishing, Lambert, $76 \mathrm{p}$.

[10] Simon, A.D. (2015) Physical Chemistry. Krasand, Moscow, 318 p.

[11] Budanov, V.V. and Maksimov, A.I. (2016) Chemical Thermodynamics. Publishing House Lan, Saint Petersburg, 320 p.

[12] Efremov, Yu.S. (2017) Statistical Physics and Thermodynamics: Uch, Allowance. 2nd Edition, Publishing House Yurait, Moscow, 209 p.

[13] Zarubin, D.P. (2017) Physical Chemistry. Infra-M, Moscow, 476 p.

[14] Schmidt, P. and Schafer, R. (2017) Methods in Physical Chemistry. John Willey \& Sons Limited, Manchester, $370 \mathrm{p}$.

[15] Atkins, P.W. and de Paula, J. (2016) Elements of Physical Chemistry. W. H. Freeman and Company, Oxford, $656 \mathrm{p}$.

[16] Yazachev, T. (2014) Physical Chemistry. Academic Publishing, Lambert, 148 p.

[17] Monk Paul, M.S. (2004) Physical Chemistry: Understanding Our Chemical World. John Wiley \& Sons Ltd., Manchester Metropolitan University, Manchester, 619 p.

[18] Rogers, D.W. (2013) Concise Physical Chemistry. John Wiley \& Sons, Brooklyn, 405 p.

[19] Malyshev, V.P., Makasheva, A.M. and Bekturganov, N.S. (2013) Viscosity, Fluidity and Density of Substances. Aspect of Chaotization. Academic Publishing, Lambert, $340 \mathrm{p}$.

[20] Malyshev, V.P., Tolymbekov, M.Z., Turdukozhayeva, A.M., Kazhikenova, A.S. and Akuov, A.M. (2010) Melt Flow-Destruction of Cluster Associations. Melts, 6, 43-49.

[21] Malyshev, V.P. and Turdukozhayeva, A.M. (2011) Refinement of the Cluster-Associate Model of Melt Viscosity Based on the Influence of Temperature on the Degree of Cluster Association. Melts, 6, 72-79.

[22] Malyshev, V.P. and Makasheva, A.M. (2018) Boltzmann's Distribution as the Basis for the Universal Expression of the Activation Energy of Viscous Flow, Chemical Reactions and Mechanical Destruction. Non-Ferrous Metals, 10, 6-12. https://doi.org/10.17580/tsm.2018.10.01

[23] Dickerson, R., Gray, G. and Height, J. (1982) Basic Laws of Chemistry. Vol. 2, Mir, Moscow, $654 \mathrm{p}$.

[24] Rabinovich, V.A. and Havin, Z.Y. (1978) Brief Chemical Reference. Chimiya, L., $316 \mathrm{p}$. 